\title{
The Effect of Strategic Intuition, Business Analytic, Networking Capabilities and Dynamic Strategy on Innovation Performance: The Empirical Study Thai Processed Food Exporters*
}

\author{
Somnuk AUJIRPONGPAN ${ }^{1}$, Yuttachai HAREEBIN ${ }^{2}$
}

Received: September 08, 2019 Revised: November 01, 2019 Accepted: November 15, 2019

\begin{abstract}
The purpose of this study is to examine the predictive effects of intuition, business analytic, networking capabilities on innovation performance. The data was collected using a cross-sectional quantitative survey. A total of 292 useable responses were collected from Thai Processed Food Exporters (TPFE). The findings also indicated that the hypothesized relationships between the independent and dependent variables fit the empirical data. Specifically, it is revealed that strategic intuition, business analytic capabilities, networkbased capabilities and dynamic capabilities had a direct effect on dynamic strategy. They also had statistically significant direct and indirect effects on dynamic performance. Based on the results of the correlation test, the researchers developed a dynamic capability model for the development of the dynamic performance of the operators, which included concepts, principles, methods, tools and guidelines. Furthermore, the impacts of intuition, business analytic, networking capabilities on dynamic strategy are also examined in this study. It makes a considerable contribution to the existing literature on dynamic strategy of TPFE, particularly in regards to explaining the performance.
\end{abstract}

Keywords : Strategic Intuition, Business Analytic, Networking Capabilities, Dynamic Strategy, Innovation Performance, Food Exporter

JEL Classification Code : L26, L66, M11, M40, O15

\section{Introduction}

Technological advances have resulted in fierce competition in which many organizations use advanced technology to create or develop innovations (Lee \& $\mathrm{Li}$, 2014). Countries that use knowledge to innovate will drive the economy to grow at a global level and into the global

\footnotetext{
* This research was partially supported by the new strategic research (P2P) project, Walailak University, Thailand.

1 First Author and Corresponding Author, Associate Professor, School of Management, Walailak University, Thailand. [Postal Address: School of Management Academic Building 3, Walailak University, 222 Thai Buri, Tha Sala Nakhon Si, Thammarat 80160, Thailand] Email: asomnuk@wu.ac.th

2 Lecturer, Faculty of Management Science, Phuket Rajabhat University, Thailand. Email: yuttachai.mas@gmail.com

(c) Copyright: Korean Distribution Science Association (KODISA)

This is an Open Access article distributed under the terms of the Creative Commons Attribution Non-Commercial License (http://Creativecommons.org/licenses/by-nc/4.0/) which permits unrestricted noncommercial use, distribution, and reproduction in any medium, provided the original work is properly cited.
}

market (Redding, 2016; Redding \& Drew, 2015, Tong, 2014). In today's competitive industry, innovation is a key role in the application and alignment of organizational resources for product and service creation and value creation (Kostopoulos et al., 2011). It is imperative for entrepreneurs make quick adjustments and to adopt the right strategies as a way to guide entrepreneurs in their direction of innovation (Dougherty and Dunne, 2012). Finally, the organization must apply all its resources to maximize its efficiency and effectiveness by choosing innovative strategies (Crosson \& Apaydi, 2010; Hidalgo \& D'Alvano, 2014).

Modern Organizational Management Strategy is the application of traditional management concepts and modern management concepts for the integration of organizational resources (Baath \& Walin, 2014). Every organization needs to adopt strategies to increase organizational effectiveness.3 Key perspectives on resources are: 1) Leadership is the key to change, forward-looking, brave, challenging, futile, 
selective of strategies, and intelligent. (Duggan, 2013; Dimmock \& Walker, 2000). 2) The knowledge perspective is the use of information and knowledge used in organizational management to develop business decision making processes based on factual information (Haug, Arlbjørn, \& Pedersen, 2009). And last perspective, network perspective is the interconnected workgroup structure of the workgroup or department that is cross-linked to the purpose of exchanging resources, such as knowledge, technology other for the develop to Innovative Capabilities (Ranganathan \& Rosenkopf, 2014). These three perspectives are the creation or change of capabilities and resources that the organization has both external and internal to respond to changing conditions (Hareebin et al., 2016).

For entrepreneurs in Thailand today, they need to adapt to the government's policy of bringing the country into the "Thailand 4.0" model that wants to develop continuously from agriculture, light industry and heavy industry to drive the country with innovation. It transforms from commodity to innovate with the drive of technology, creativity in particular, the processed food industry is expected to be driven by the country's overall industrial development as set out in the master plan for Thailand's industrial development during 2012-2041, so that it can increase the value of agricultural produce. The government has supported many factors such as budget, research promotion and innovation clusters. The food market in Thailand is 59.8 percent in Asia. Japan, CLMV countries, ASEAN and China. Main products are rice, sugar, chicken, shrimp, canned tuna. canned pineapple, tapioca and condiments. The export volume and value increased, there are three groups: sugar, chicken and seasoning. Canned pineapple and tapioca starch, but the problem with the market is that foreign market fluctuations are a result of the global trade liberalization (Ministry of Commerce, 2012; Ministry of Industry, 2011).

Therefore, operators of processed food exports must adopt a modern enterprise management strategy that is managed or managed as a directional process. By introducing traditional concepts and modern management concepts, we can use all available resources to effectively and effectively implement our operations. This research aims to find out the relationship between dynamic and innovative approaches based on three basic views of organizational resources: Leadership perspective, knowledge perspective and the network perspective to make a difference in running the business over competitors and compete with other businesses on the international level.

\section{Theoretical Background}

This paper describes the relationship between the enhancement of strategic capabilities and innovation as a result of resource development that needs to be upgraded simultaneously with good strategies (Daniel \& Wilson, 2003; Roy \& Roy, 2004). Dynamic perspective is the organization's ability to adapt to the changing environment
(Barreto, 2010). Due to current advances in technology, advances in the fast-moving product life cycle, there may be imitations of goods and services (Ireland et al., 2006). Therefore, the organization must continually develop its strategy to influence the organization's innovation in terms of its performance, as well as the development of resources for integration, rehabilitation and new capacity building (Helfat et al., 2007).

Describe the relationship of the conceptual framework. This research key issues are the dynamics of innovation and innovative performance. And another interesting point. Supporting factors that influence dynamic strategies. The research team selected the following factors in the evolution of the importance of resource base theory (RBV). It has started to focus on tangible and intangible assets, which most academics consider intangible assets to be more important (Wade \& Hulland, 2004). And later in the era of knowledge-based economy, which is the era of importance. Tacit knowledge and knowledge are the two sources of knowledge that can be developed into the knowledge of the organization (Nonaka \& Takevchi, 1995). At the age of interconnectedness the organization exchanges knowledge, experiences, and collaborates as a network to strengthen sustainable competition by increasing productivity and innovation (Hareebin et al., 2016).

Thus, the researcher chose the perspective of the importance of supporting factors (Figure 1): the perspective of strategic resources, the strategic intuition, and the test of the degree of strategic instinct to synthesize strategies or methods of competition for organizational success (Myers, 2002; Duggan, 2013). The knowledge perspective is business analytic capabilities. It is a tool of the organization to create the ability to analyze information, motivate decision makers to solve problems or solve business problems (Collins \& Porras, 1991; Yang \& Chan, 2007; Davenport \& Harris, 2007). Finally, the networking perspective is to test the level of business networking to provide opportunities for business expansion or mutual exchange of resources under shared interests (Walter, Auer, \& Ritter, 2006; Ranganathan \& Rosenkopf, 2014).

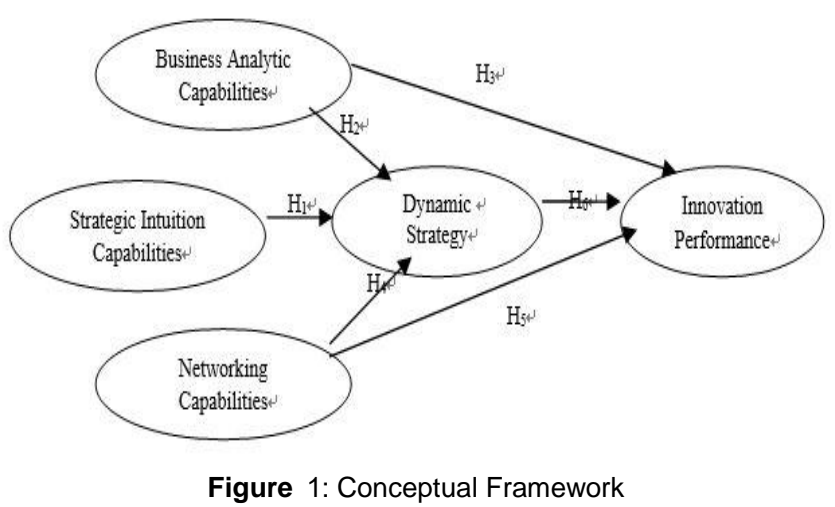




\section{Conceptual Background and Hypothesis}

\subsection{Strategic Intuition}

The success or failure of organizational propulsion is partly based on management decisions (Harris, 2009; Leavy, 2016). So the new paradigm of leadership education in the 21 st century is the focus of strategic leaders. Have ideas to look into the future and create new challenges at all times (Srichan et al., 2016). This is related to the ability to choose a strategy for addressing the organization's problems, to eliminate weaknesses, and to work in line with the organization's vision (Kouzes \& Posner, 2012; Duggan, 2013). The special ability that lies within the unreachable leader is the ability to perceive the possibilities. Strategic Intuition is the mind's way of perceiving and making decisions in a timely manner, based on the knowledge gained from the experience. Premonition can be perceived by certain events in the future through intuition (Miller \& Ireland, 2005).

"Strategic Intuition", William Duggan is a scholar of strategic insight, says that the success of a strategic insight development phase depends on creating a mental state of mind when creating harmony. In the past and the present, and out of the original frame of mind that is dominated by the mental state, how many views together. The components of this research have been applied to a number of concepts, including: 1) Sensing Capabilities are the ability to perceive or visualize opportunities to lead the learning of judgment and evaluation to create the imagination, each of the scenarios (Bunge 1983; Allinson et al., 2000; Bradley, 2006). 2) Aggressive thinking capabilities are the thoughts and experiences of the past and present, which are framed in the future. External stimulation (Agor, 1984; Burke \& Miller, 1999; Mitchell et al., 2005). And 3) Strategic Decision Capabilities are the ability to make decisions that are within the organization's vision, with a focus on the future of business competitiveness (Riqueleme \& Watson, 2002; Kahneman, 2003; Bradley, 2006). Strategic intuition capabilities of leaders when they believe in thought and decision make a competitive advantage and achieve a goal of intuitive leadership (Duggan, 2013). This leads to the following hypotheses:

H1: Strategic Intuition Capabilities directly and positively affects Dynamic Strategy.

\subsection{Business Analytic Capabilities}

In situations where many organizations in each industry offer value-added or value-added products and technologies, the process within the organization is different from competing competitors. Analytic Capabilities can pull people's potential or organizational value out of an organization's processes. Analytics can help the organization's operational processes find the true potential of the process to support business decisions (Davenport \& Harris, 2007; Mortenson et al., 2015). Business Analytic Capabilities are a knowledge support factor that influences the dynamic strategy by focusing on people or people, who can plan, collect data, analyze data, and present analysis results to decision makers. Therefore, the determination of variables depends on the process of analysis ability, from data collection, planning, analysis and presentation (Kiron \& Shockley, 2011, Lavalle et al., (2011).

For the study of the factors within the organization in the process of business analytical capabilities of the organization, the researcher has analyzed 3 aspects: 1) Expertise Capabilities, which is the ability of the person who is relevant to supporting the strategy. It is a skillful person with experience (Jones \& Tilley, 2003; Gold et al., 2001). They have a clear understanding of the objectives of the organization. They are interested in pursuing new knowledge, creative skills, the ability to share knowledge with external experts, and apply knowledge to improve or solve the problem (Birkinshaw \& Shechan, 2002; Yang \& Chen, 2007; Tiwana et al., 2005). 2) Technology Capabilities are the basic resources of information technology of the organization. Both are hardware and software, they are linked to the performance of information technology through the network system of the organization (Yang \& Chen, 2007). The technology of the organization must be conducive to gain access to new knowledge immediately and to be effective enough to use it (Peachey, (2006). It also provides access to product knowledge and services to develop the marketing knowledge and business competitors (Collision \& Porras, 1991; Peachey, 2006). And 3) Information Capabilities are the characteristics of the ability to hold or have information and information for maximum benefit through archiving, which is useful for decision making. The organization must have sufficient information to interpret the synthesis. The database is an important part of decision making (Bevern, 2002; Davenport et al., 1998). The organization should have access to data archives that are convenient and up-to-date and have a database that meets the needs for quantitative and qualitative adoption (Freeze, 2006; Zollo et al., 2006; Bhatt, 2001). Based on the previous discussion, the following hypotheses are offered:

H2: Business analytic capabilities directly and positively affects dynamic strategy.

H3: Business analytic capabilities directly and positively affects innovation performance.

\subsection{Networking Capabilities}

There are three basic concepts of network: 1) Network is the true nature of things 2) Networks are systematic relationships and 3) Networks are structures and structures of nature (Phramaha \& Panyachit, 2013). The concept can explain dynamic changes to resource sharing as a driving 
force in organizational development (Alter \& Hage, 1993). The definition of the term refers to the web of social relationships, unity, power, cohesiveness and mutual support (Schuler, 1996). And Paul (1997), meaning "network" refers to a group of people or organizations that voluntarily exchange information, information, or activities together and remain free to conduct their activities.

For a business perspective, it must describe the dimension of a collaborative, mission-oriented relationship or operate to reduce costs and enhance business competition and still look at the organization in the corner. Look at the network as a resource base in network-based model (Capaldo, 2007; Dittrich \& Duysters, 2007; Edvardsson et al., 2008). Research defines networking as the ability of an organization to form an organization with a coherent working structure of a work group or department, which is cross-linked to exchange purposes, resources such as knowledge, technology and so on to develop organizational capabilities to enhance the capacity of each organization. The network has a singularity and not against each other.

Networking Capabilities In this paper, we explore three main areas of application of $\mathrm{Mu}$ and Benedetto (2012) is 1) Networking Capabilities: In organizations that can search for networks outside the organization at the local or international level, there is a need for a clearer understanding of the structure of authority. To realize the goal of networking together (Hagedoorn, 2006). 2) Managing network capacities is the management of the rules and functions of the interpersonal communication system and the mode of exchange (Walter et al., 2006). Finally, Leveraging networks Capabilities is a continuum of continuous activity, with the most incentive for members to stay on the network and giving them a sense of ownership of resources (Homburg \& Fürst, 2005). Networking Capabilities are another of the organization's ability to increase strategic capabilities in changing situations (Dittrich \& Duysters, 2007; Mu \& Benedetto, 2012).

H4: Networking Capabilities directly and positively affect dynamic strategy.

H5: Networking Capabilities directly and positively affect innovation performance.

\subsection{Dynamic Strategy Capabilities}

Utilizing the resources and capabilities of organizations in a stable state may not be enough to meet the challenges of today's competitive business. (Eisenhardt \& Martin, 2000). Managing the organization's resources to be ready and able to handle the challenges of constraints, the dynamic organizational strategy model can manage resources under conditions that are conditional, by enhancing performance, the organization has the potential to achieve its goals (Mintzberg \& Waters, 1985). For businesses with high growth rates, the same high uncertainty is required. Dynamic Strategy Development and Strategic Learning to meet strategic needs and learn to advance into the future (Baath \& Wallin, 2014).

For this research, the study of dynamic strategies is based on the concept of Mintzberg and Waters (1985). "Enhancing strategic capabilities in the form of dynamics or capabilities that enable strategic processes to be effective and affect the organization's effectiveness in resource management and organizational development, with a changing environment ". The three elements are: 1) Intended Strategy is an organization's planned concept, ranging from external auditing or analytical work at the industry level, and a new resource analysis step to determine the direction of the organization (Chen et al., 2007; Nadkarmi \& Nakarayanan, 2007; Sneddon et al., 2009). 2) Emergent Strategy is a strategy to adapt to specific problems and it must be used in conjunction with the plan set by the executive. It is also under the clear structure and the direction of the goal (Moncrieff, 1999; Fuller-Love \& Cooper, 2000). Finally, Strategic Learning is learning as the main process of data entry for continuous planning, with short and long term preparation in the form of participation to change in policy for the development of new knowledge (Fiol \& Lyles, 1985; Moncrieff, 1999). Therefore, the strategic flexibility or the ability of dynamic strategies helps organizations achieve operational and innovation outcomes, such as new products. That meet the needs of customers. Or even improve the process or reduce the cost of production. Which led to the assumption that:

H6: Dynamic Strategy Capabilities directly and positively affects innovation performance.

\subsection{Innovation Performance}

Innovation is an important tool for entrepreneurs to create competitive advantage, market opportunities, and business success, driven by entrepreneurial change and make a difference in business (Drucker, 2002; Dundon, 2002). In the context of the organization. The Organizational Context has provided researchers with a categorization of innovations by bringing Schumpeter's concept to develop and categorize innovation in three categories: Product Innovation, Process Innovation, Strategic Innovation (Manual, 2005). Boer and During (2010) defined the outcome of the methodology developed for use in the production of goods and services, using the main goals of the innovation process. Reduce lead time and cost of operation. Defining the perspective of talent and resources in the organization. It is the ability to innovate and develop differently, as well as to increase the economic value and achieve innovation (Guan \& Ma, 2003). Finally, the view of efficiency and effectiveness has been defined by Ar and Baki (2011). The innovative performance of an organization is the concept of the efficiency of innovative products and processes. Innovation involves the introduction of new or improved products or services to the marketplace and will focus on Identifying new customer needs, product quality, 
and developing strategies that extend into the marketplace effectively.

Nowadays, academics have created innovative performance indicators, such as financial views, which take into account return on assets (ROA), return on investment (ROI) and Profitability Ratio (Enz, Canina, \& Walsh, 2001; Chu, 2009). The focus and results of non-financial innovation are: 1) Newness 2) Economic Benefits 3) Creativity Ideal (Utterback \& Suarez, 1993; Smits, 2002; DTI, 2004; Schilling, 2008). Process perspective is to improve the speed of product production by innovating new technologies to improve processes and accelerate production (Govindarajan \& Kopalle, 2006). The market view is to increase the demand and satisfaction of customers for innovative products. And the market share of the company has increased steadily. And finally, the view of the efficiency of product innovation and innovation of the measurement process. Technical improvements even in the production process (Bell, 2005; Ritter \& Gemünden, 2004). The use of such indicators depends on the application to the business group.

\section{Methodology}

\subsection{Sampling and Procedures}

The researcher uses the demographic data from the Thailand's Exporters Directory database of the Ministry of Commerce. Interested in exporting processed food, total number of 2,752. This study uses a purposive sampling technique. Measurement of scales using 5-level scale based on Likert Scale and content validity by five experts. There were 78 questions, 4 items with IOC values did not meet criteria, leaving 74 questions, and reliability was tested with 124 samples (31.19\% of the sample). The questionnaires are as shown in Table 1, The coefficients of confidence were generally higher than 0.700 (Cronbach's alpha coefficient). Collection of data to meet the conditions agreement in the analysis of structural equation. The minimum sample size used was 280 samples, which corresponded to the number of variables studied in 20 to 1 variables (Wiratchai, 1999). Of the 400 questionnaires, 292 respondents answered 73 percent. The research was conducted between August 2560 and December 2017. The questionnaires were mailed, which was suitable for a large number of scattered research.

Table 1: Result of Reliability Test

\begin{tabular}{|l|c|}
\hline \multicolumn{1}{|c|}{ Variables } & Cronbach's Alpha \\
\hline Strategic Intuition & 0.869 \\
\hline Business Analytic Capabilities & 0.856 \\
\hline Networking Capabilities & 0.815 \\
\hline Dynamic Strategy & 0.824 \\
\hline Innovation performance & 0.896 \\
\hline
\end{tabular}

Data analysis consists of 1) Factor Analysis by Confirmatory Factor Analysis to study the consistency of the structural equation model with empirical data. 2) Pearson's Product-Moment coefficient, which analyses the relationship between the components of each factor. 3) Structural Equation Modeling (SEM), an analysis to test the consistency of the linear relationship model developed by the researcher with the empirical data. Data were collected from questionnaire using the LISREL program.

\subsection{Variables and Measures}

\subsubsection{Strategic Intuition}

A view of measuring the potential of a leader in perceiving awareness of the future possibilities to create a path to the goal. 1) Sensing Capabilities (Bunge, 1983; Allinson et al., 2000; Bradley, 2006). 2) Aggressive Thinking Capabilities (Agor, 1984; Burke \& Miller, 1999; Mitchell et al., 2005) and 3) Strategic Decision Capabilities (Riqueleme \& Watson, 2002; Kahneman, 2003; Bradley, 2006).

\subsubsection{Business Analytic Capabilities}

A study of factors within an organization that is in the process of analytical ability to support business decisions. The researcher has analyzed 3 issues.1) Expertise Capabilities (Jones \& Tilley 2003; Freeze, 2006; Yang \& Chen, 2007). 2) Technology Capabilities (Collision \& Porras, 1991; Peachey, 2006); and 3) Information Capabilities (Davenport et al., 2010; Bevern, 2002).

\subsubsection{Networking Capabilities}

It is the process of building the capacity of an organization to exchange resources or learn to plan together for the synergy. The indicators are based on the concept of $\mathrm{Mu}$ and Benedetto (2012). There are 3 items: 1) Finding network Capabilities 2) Managing network capacities and 3) Leveraging network Capabilities. Measure the process perspective towards competence, dynamic strategy, and innovation creation.

\subsubsection{Dynamic Strategy Capabilities}

The strategic flexibility or ability of a dynamic strategy helps organizations achieve operational and innovation outcomes in a process-oriented perspective. Three elements are considered. 1) Intended Strategy 2) Emergent Strategy and 3) Strategic Learning (Mintzberg \& Waters, 1985; Baath \& Wallin, 2014).

\subsubsection{Innovation Performance}

The researcher proposed 2 view be measured as product innovation. And the innovation of the process because the food processing industry exports are focused on the process of production for export. Measurement Innovation performance is the improvement and development of new products through the introduction of good customer feedback and the speed of new product offerings (Tsai et al., 2011; Zhang \& Duan, 2010; Sidhu, et al., 2007). Using new production processes or advanced technologies that result in 
faster production rates (Bell, 2005; Ritter \& Gemünden, 2004; Govindarajan \& Kopalle, 2006).

\section{Data Analysis and Results}

Validation of the strategic intuition measurement model Business analysis capabilities Network capabilities Dynamic strategy and dynamic performance by determining the component fit measure in the measurement model (Measurement Model).

Strategic intuition measurement model, business analysis capabilities, network capabilities, dynamic ability, dynamic strategy and the dynamic performance results are also categorical (Discriminant Validity) due to the exactness of the measure of each construct that can be separated to measure only their own subject not included with the gauge of the structure, other variables considering the value The interested column is higher than all cross construct correlation values in the same column. Indicates that the metric has exactly the same classification in all the other structures, as described in Table 2 and 3.
Table 2: Composite Reliability Values

\begin{tabular}{|c|c|c|c|c|}
\hline & $\begin{array}{c}\text { Measurement } \\
\text { items }\end{array}$ & Loading & CR & PKS \\
\hline \multirow[t]{3}{*}{ Strategic Intuition } & SI & 0.7631 & 0.9459 & 0.5783 \\
\hline & $\mathrm{SI} 2$ & 0.8743 & & \\
\hline & $\mathrm{SI} 3$ & 0.8561 & & \\
\hline \multirow{3}{*}{$\begin{array}{l}\text { Business Analytic } \\
\text { Capabilities }\end{array}$} & BCA1 & 0.8238 & 0.9982 & 0.5974 \\
\hline & BCA2 & 0.6885 & & \\
\hline & BCA3 & 0.7548 & & \\
\hline \multirow{3}{*}{$\begin{array}{l}\text { Networking } \\
\text { Capabilities }\end{array}$} & NBC1 & 0.8629 & & \\
\hline & NBC2 & 0.8327 & & \\
\hline & NBC3 & 0.7297 & & \\
\hline \multirow[t]{3}{*}{ Dynamic Strategy } & DS1 & 0.7098 & 0.9639 & 0.991 \\
\hline & DS2 & 0.7351 & & \\
\hline & DS3 & 0.7825 & & \\
\hline \multirow{4}{*}{$\begin{array}{l}\text { Innovation } \\
\text { performance }\end{array}$} & IP1 & 0.8458 & 0.9439 & 0.527 \\
\hline & IP2 & 0.6458 & & \\
\hline & IP3 & 0.6943 & & \\
\hline & IP4 & 0.8489 & & \\
\hline
\end{tabular}

Notes: *Composite reliability $(\mathrm{CR})=($ square of the summation of the factor loadings) $/$ (square of the summation of the factor loadings)+(square of the summation error variances)\}

${ }^{\star *}$ Average variance extracted $(P K S)=$ (summation of the square of the factor loadings $) /\{$ (summation of the square of the factor loadings)+(summation of the error variances)\}

Table 3: Discriminant Validity Analysis

\begin{tabular}{|c|c|c|c|c|c|c|c|}
\hline \multirow{2}{*}{ Construct } & \multirow{2}{*}{$\rho c$} & \multirow{2}{*}{$\rho v$} & \multicolumn{5}{|c|}{ Cross construct correlation } \\
\hline & & & SI & BAC & NBC & DS & DP1 \\
\hline BAC & 0.910 & 0.772 & 0.407 & 0.879 & & & \\
\hline DS & 0.914 & 0.780 & 0.339 & 0.469 & 0.364 & 0.883 & \\
\hline DP & 0.858 & 0.601 & 0.305 & 0.518 & 0.378 & 0.674 & 0.775 \\
\hline
\end{tabular}

The results of the structural equation model analysis of the causal relationship model of strategic intuition Business analysis capabilities, Network capabilities, Dynamic ability, Dynamic strategy and Dynamic performance: Figure 2 (After adjusting the model) Harmony of Overall Model Fit Measure. It was found that the chi-square statistic / class of independence $\left(\chi^{2} / d f\right)$ was 2.34 which was less than 3 . Defined the group index defined at the level of more than or equal to 0.90 found that all indices are GFI $=0.98$, AGFI $=$
$0.96, \mathrm{NFI}=0.96, \mathrm{IFI}=0.97, \mathrm{CFI}=0.96$ will pass the specified index criteria at a level less than 0.08. Index RMR $=0.03$ and RMSEA $=0.03$ meet the same criteria. Therefore concluded that Structural equation model of the causal relationship model of Strategic intuition, Business analysis capabilities, Network capabilities, Dynamic ability, Dynamic strategy and the Dynamic performance that is developed in harmony with empirical data.

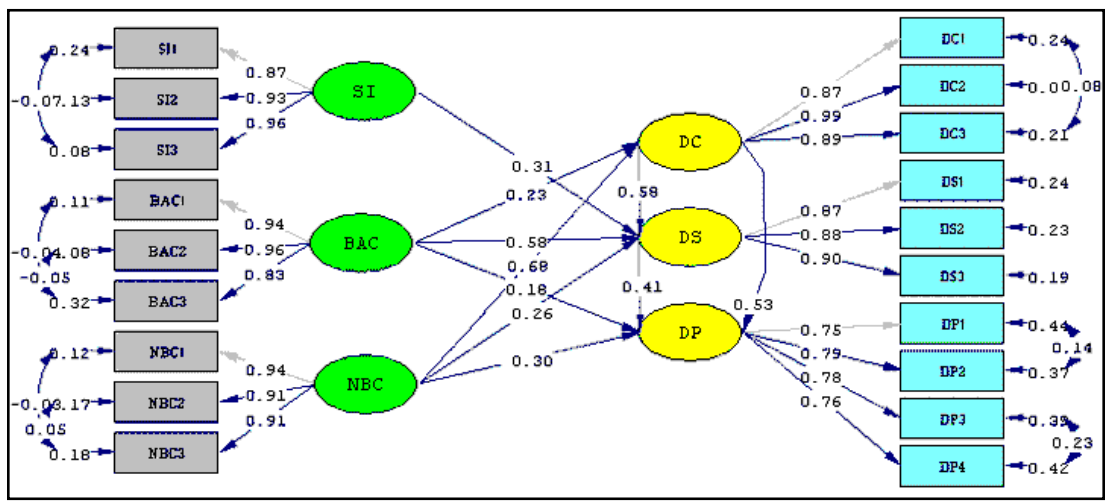

Chi-square $=305.94, \mathrm{df}=131, \chi^{2} / d f=, 2.34 \mathrm{NFI}=0.96, \mathrm{IFI}=0.97, \mathrm{CFI}=0.97, \mathrm{GFI}=0.98, \mathrm{AGFI}=0.96, \mathrm{RMR}=0.03, \mathrm{RMSEA}=0 ., 03^{*} \mathrm{P}<0.05$ Figure 2: The Structural Equation Model 


\section{Discussion}

The development of the components of the dynamic strategy in this research is based on the resource base concept. (Resources-based view) in the perspective of dynamic for linking dynamic strategies with innovative capabilities that can explain the strategic processes that are reorganizing resources that are both organizational capabilities in various aspects In response to changes in the market to be developed into the core competencies of the organization the dynamic strategy is therefore defined as raising the level of strategic ability in the form of dynamics or capabilities that make strategic processes effective and affecting the effectiveness of the organization. For the management of resources and developing the organization to be ready with the changing environment under the constraints of both internal and external environment. Intended Strategy, Emergent Strategy and Strategic Learning. The formulation of strategies, goals, policies, operational plans resource allocation from long-term investments to short-term proportions There is a follow-up model to consider and analyze the environment and create new knowledge every 5-3years and entrepreneurs also have new products to make a difference and there are indicators in the form of performance market share the demand or satisfaction from customers continuously increases. And the margin of new products increases every year to indicate the success of strategic operations.

Small and medium enterprises can use research data to be used as a form or guideline for the implementation of factors affecting dynamic strategies and dynamic results. It can also be used to compare resources between organizations, especially SMEs that is in the same industry. Which, if entrepreneurs have the ability to search or develop various factors such as Strategic insight, Business analysis capabilities, Network capabilities and Dynamic capabilities to increase the ability of the organization In order to achieve the objective of the business or even reducing obstacles that exist in the organization which at present, an asset that has a competitive advantage is still the main issue that every entrepreneur must consider in using as an organizational performance. This may require the ability to integrate resource management. To create efficiency as well therefore, the researcher summarizes the important factors in the perspective of having resources. To create a competitive advantage according to the properties of VRIN (Valuable, Rare, Imperfectly imitation and Non-Substitutable).

\section{Implications}

The importance in the dimension of systematic theoretical explanations this research article describes the relationships that are related to the upgrading of strategic Capability, Dynamic Capability and related resources that the organization possesses to create competitive advantage.
Especially the dynamic ability that requires resources and capabilities that must be created at the same time. Dynamic capabilities can be effective only when the organization has a good strategy (Daniel \& Wilson, 2003; Roy \& Roy, 2004; Teece, (2014A good strategy must be something that is not fixed and without a formula. The author views that the concept of Mintzberg (2013) is a flexible concept that is not given any meaning. By interpreting the meaning of the strategy depends on the use of each context in order to get a guideline of competitive advantage.

Resource base concept (Resources-based view) in view of the dynamic is the adjustment of organizational resources in accordance with the changing conditions continuously (Barreto, 2010; Leskova - Sacapan \& Bastic, 2007). Porter (1991) is a dynamic transformation that has a theoretical foundation from the dynamic theory of strategy, with important elements that are the source of a consistent and must-have strategy. These are constantly updated. Learning of the core resources of the organization and the organizational structure that is flexible. This research therefore requires a systematic description of the relationship between strategic capabilities. Dynamic ability and strategic changes to create strategic effectiveness of the organization.

\section{Limitation}

This research is a collection of data from entrepreneurs who have management positions with positions in strategic decisions, power and knowledge of the organization. At the beginning, it was found that the response rate was low, which affected the reliability of data collection. In addition, there are differences in each industry, as research is a collection of information for small and medium enterprises in specific groups that combine many industries together. Which the analysis results may not directly represent the representation of each industry. Therefore, each industry should be researched to increase the concentration and theoretical firmness of each industry in Thailand.

Future studies should add to the study of various variables that affect dynamic strategy capabilities. Dynamic performance and the competitiveness of small and medium enterprises. Which may be studied both by adding factors that affect and further study of the indicators of each factor from the existing 3to 4indicators of each element to increase the suitability and strength of the model as well. This also increases the theoretical firmness that confirms the accuracy in the most current perspective.

More detailed study of dynamic performance measurement and study of the effectiveness of organizational operations in other dimensions which covers both financial indicators and non-financial indicators. Which may be labor productivity variables or even the satisfaction of those who have a stake in the indicators in the model that they want to study and must be important to the current and 
future competition dimension and also to look forward to predicting the situation in the short and long term In order to prepare the entrepreneurs for adjustment and still have to achieve the objectives of the organization.

\section{References}

Agor, W. H. (1984). Using intuition to manage organisations in the future. Business Horizons, 27(5), 49-54.

Allinson, W. C., Chell, E., \& Hayes, J. (2000). Intuition and entrepreneurial behaviour. European Journal of work and Organizational Psychology, 9(1), 31-43.

Alter, C., \& Hage, J. (1993). Organizations working together. Newbury Park, CA: Sage Publications.

Ar, I. M., \& Baki, B. (2011). Antecedents and performance impacts of product versus process innovation: empirical evidence from SMEs located in Turkish science and technology parks. European Journal of Innovation Management, 14(2), 172-206.

Baath, S., \& Wallin, L. (2014). Dynamic strategy in high growth firms: The importance and implication of dynamic strategy development in phases of high growth. London, England: Routledge. Retrieved August 20, 2019 from http://www.diva-portal.org/smash/record.jsf?pid= diva2\%3A725222\&dswid $=-5370$

Barreto, L. (2010). Dynamic capabilities: A review of past research and an agenda for the future. Journal of Management, 36(1), 256-280.

Bell, G. G. (2005). Clusters, networks, and firm innovativeness. Strategic Management Journal, 26(3), 287-295.

Bevern, V. J. (2002). A model of knowledge acquisition that refocuses knowledge management. Journal of Knowledge Management, 4(6), 18-22.

Bhatt, G. (2001). Knowledge management in organizations: Examining the interaction between technologies, techniques, and people. Journal of Knowledge Management, 5(1), 68-75.

Birkinshaw, J., \& Sheehan, T. (2002). Managing the knowledge lifecycle. London, England: London Business School.

Boer, H., \& During, W. E. (2010). What innovation? A comparison between product, process and organizational innovation International. Journal of Technology Management, 22(3), 83-107.

Bradley, R. T. (2006). The Pscyhophysiology of intuition: A quantum holographic theory of nonlocal communication. World Futures. Journal of General Evolution, 63, 61-97.

Bunge, M. A. (1983). Treatise on basic philosophy. Dordrecht, Holland: Reidel Publishing.

Burke, L. A., \& Miller, K. M. (1999). Taking the mystery out of intuitive decision making. Academy of Management Executive, 13(4), 91-98.

Capaldo, A. (2007). Network structure and innovation: The leveraging of a dual network as a distinctive relational capability. Strategic Management Journal, 28(6), 585608.

Chen, M. J., Su, K. H., \& Tsai, W. (2007) .Competitive tension: The awareness-motivation capability perspective. Academy of Management Journal, 5(1), 101-.118

Chu, W. W. (2009). Can Taiwan's second movers upgrade via branding? Research Policy, 38(6), 1054-1065.

Collins, J. C., \& Porras, J. I. (1991). Organizational vision and visionary organizations. California Management Review, 34(1), 30-52.

Collison, C., \& Parcell, G. (2004). Learning to fly: Practical knowledge management from some of the world's leading learning organizations. London, UK: Harper Collins Business.

Crossan, M. M., \& Apaydin, M. (2010). A multidimensional framework of organizational innovation: A systematic review of the literature. Journal of Management Studies, 47(6), 1154-1191.

Daniel, E. M., \& Wilson, H. N. (2003). The role of dynamic capabilities in E-Business transformation. European Journal of Information System, 12(4), 282-296.

Davenport, T. H., \& Harris J. G. (2007). Competing on analytics: The new science of winning. Boston, MA: Harvard Business Press.

Davenport, T., Harris, J. G., \& Morison, R. ( .(2010Analytics at work: Smarter decisions, better results. Boston, MA: HBR Press.

Dimmock, C., \& Walker, A. (2000). Globalisation and societal culture: Redefining schooling and school leadership in the twenty-first century. Journal of Comparative and International Education, 30(3), 303312.

Dittrich, K., \& Duysters, G. (2007). Networking as a means to strategy change: The case of open innovation in mobile telephony. Journal of Product Innovation Management, 24(6), 510-521.

Dougherty, D. J., \& Dunne, D. D. (2012). Digital science and knowledge boundaries in complex innovation. Organization Science, 23(5), 1467-1484.

Drucker, P. F. (2002). The discipline of innovation. Harvard Business Review, 68(4), 67-72.

DTI. (2004). Succeeding through innovation, creating competitive advantage through innovation: A guide for small and medium sized businesses. London, UK: Department of Trade and Industry.

Duggan, W. (2013). Strategic intuition: The creative spark in human achievement. (2nd ed.). New York: Columbia Business School.

Dundon, E. (2002). The seeds of innovation: Cultivating the synergy that fosters new ideas. New York, NY: AMACOM.

Edvardsson, B., Holmlund, M., \& Strandvik, T. (2008). Initiation of business relationships in service-dominant settings. Industrial Marketing Management, 37(3), 339350.

Eisenhardt, K. M., \& Martin, J. A. (2000). Dynamic 
capabilities: What are they? Strategic Management Journal, 21(2), 1105-1121.

Enz, C. A., Canina, L., \& Walsh, K. (2001). Hotel-industry averages: An inaccurate tool for measuring performance. Cornell Hotel \& Restaurant Administration Quarterly, 42(6), 22-32.

Fiol, M. C., \& Lyles, M. A. (1985). Organizational learning. Academy of Management Review, 10(4), 803-813.

Freeze, R. D. (2006). Relating knowledge management capability to organizational outcomes. Doctorial dissertation, Arizona State University.

Fuller-Love, N., \& Cooper, J. (2000). Deliberate versus emergent strategies: A case study of information technology in the Post Office. International Journal of Information Management, 20(3), 209-223.

Gold, A. H., Malhotra, A., \& Segars, A. (2001). Knowledge management: An organizational capabilities perspective. Journal of Management Information Systems, 18(1), 185-214.

Govindarajan, V., \& Kopalle, P. K. (2006). Disruptiveness of innovations: Measurement and an assessment of reliability and validity. Strategic Management Journal, 27(2), 189-199.

Guan, J., \& Ma, N. (2003). Innovative capability and export performance of Chinese firms. Technovation, 23(9), 737-747.

Hagedoorn, J. (2006). Understanding the cross-level embeddedness of interfirm partnership formation. Academy of Management Review, 31(3), 670. https://doi.org/10.5465/amr.2006.21318924

Hareebin, Y., Aujirapongpan, S., \& Siengthai, S. (2016). The network-based capability and innovative capabilities of small and medium-sized enterprises (SMEs). Executive Journal, 36(2), 79-88.

Harris, A. (2009). Creative leadership: Developing future leaders. Management in Education, 23(1), 9-11.

Haug, A., Arlbjørn, S. A., \& Pedersen, A. (2009). A classification model of ERP system data quality. Industrial Management \& Data Systems, 109(8), 10531068.

Helfat, C., Finkelstein, S., Mitchell, W., Peteraf, M., Singh, H., Teece, D., \& Winter, S. (2007). Dynamic capabilities: Understanding strategic change in organizations. Malden, MA: Blackwell.

Hidalgo, A., \& D'Alvano, L., (2014). Service innovation: Inward and outward related activities and cooperation mode. Journal of Business Research, 67(5), 698-703.

Homburg, C., \& Fürst, A. (2005). How organizational complaint handling drives customer loyalty: An analysis of the mechanistic and the organic approach. Journal of Marketing, 69(3), 95-114.

Ireland, D., Hoskisson, E. \& Hitt, A. (2006). Understanding business strategy: Concepts and cases. Mason, $\mathrm{OH}, \mathrm{UK}$ : Thomson Higher Education.

Jones, O., \& Tilley, F. (2003). Competitive advantage in SMEs: Towards a conceptual framework. West Sussex, England: John Wiley \& Sons.
Kahneman, D. (2003). A perspective on judgment and choice. American Psychologist, 58(9), 697-720.

Kiron, D., Shockley, R., Kruschwitz, N., Finch, G., \& Haydock, M. (2011). Analytics: The widening divide. Sloan Management Review, (3)53,1-.22

Kostopoulos, K., Papalexandris, A., Papalexandris, A., Papachroni, M., \& Ioannou, G. (2011). Absorptive capacity, innovation, and financial performance. Journal of Business Research, 64(12), 1335-1343. DOI: 10.1016/j.jbusres.2010.12.005

Kouzes, J. M., \& Posner, B. Z. (2012). The leadership challenge: How to make extraordinary things happen in organizations (5th ed.). San Francisco, CA: Jossey-Bass.

Lai, Y.-L., Hsu, M.-S., Lin, F.-J., Chen, Y.-M., \& Lin, Y.-H. (2013). The effects of industry cluster knowledge management on innovation performance. Journal of Business Research, 67(1), 734-739.

Lavalle, S., Lesser, E., Shockley, R., Hopkins, M. S., \& Kruschwitz, N. (2011). Big data, analytics and the path from insights to value. MIT Sloan Management Review, 52(2), 21-32.

Leavy, B. (2016). Effective leadership today-character not just competence. Strategy \& Leadership, 44(1), 20-29.

Lee, K. \& Li, S. (2014). Possibility of a middle income trap in China: Assessment in terms of the literature on innovation, big business and inequality. Frontiers of Economics in China, 9(3), 370-397.

Leskovar-Spacapan, G., \& Bastic, M. (2007). Differences in organizations' innovation capability in transition economy: Internal aspect of the organizations' strategic orientation. Technovation, 27(9), 533-546.

Manual, O. (2005). Guidelines for collecting and interpreting innovation data $\left(3^{\text {rd }}\right.$ ed.). London, England: OECD-Eurostat.

Miller, C. C., \& Ireland, R. D. (2005). Intuition in strategic decision-making, friend or foe in the fast-paced 21 st century. Academy of Management Executive, 19(1), 1930.

Ministry of Commerce. (2012). Database of Thailand Trading Report. Retrieved December 1, 2017, from, http://www2.ops3.moc.go.th/ [in Thai]

Ministry of Industry. (2011). National Industrial Development Master Plan for 2012-2031. Retrieved December 12, 2017, from http://www.industry.go.th /5/Forms/AllItems.aspx [in Thai]

Mintzberg, H., \& Waters, A. (1985) .Of strategies deliberate and emergent. Strategic Management Journal, 6(3), 257-.272

Mintzberg, H. (2013 .(The rise and fall of strategic planning $\left(13^{\text {th }}\right.$ ed.). NY: Prentice-Hall.

Mitchell, J. R., Friga, P. N., \& Mitchell, R. K. (2005). Untangling the intuition mess: Intuition as a construct in entrepreneurship research. Entrepreneurship Theory and Practice, 29(6), 653-679.

Moncrieff, J. (1999). Is strategy making a difference? Long Range Planning, 32(2), 273-276.

Mortenson, M. J., Doherty, N. F., Robinson, S. (2015). 
Operational research from Taylorism to terabytes: A research agenda for the analytics age. European Journal of Operational Research, 241(3), 583-595.

Mu, J., \& Benedetto, C. A. (2012). Networking capability and new product development. IEEE Transactions on Engineering Management, 59(1), 4-19.

Myers, D. (2002). Intuition: Its powers and perils. New Haven, CT: Yale University Press.

Nadkarni, S., \& Nakarayanan, V. K. (2007). Strategic schemas, strategic flexibility, and firm performance: The moderating role of industry clockspeed. Strategic Management Journal, 28(3), 243-270. https://doi.org/10.1002/smj.576

Nonaka, I., \& Takeuchi, H. (1995). The knowledge-creating company: How Japanese companies create the dynamics of innovation. Oxford, UK: Oxford University Press.

Paul, S. (1997). Networking for development. London: International Forum for Rural Transport and Development.

Peachey, T. (2006). Supporting complex problems: An examination of churchman's inquirers a knowledge management foundation. Retrieved August 20, 2019 from http://handle.dtic.mil/

Phramaha, S. A., \& Panyachit, S. (2013). The model of social learning network in Buddhist tourism. Journal of Social Science Srinakharinwirot Unversity, 16(1), 115127.

Porter, M. E. (1991). Towards a dynamic theory of strategy. Strategic Management Journal, 12, 95-117.

Ranganathan, R., \& Rosenkopf, L. (2014). Do ties really bind? The effect of knowledge and commercialization networks on opposition to standards. The Academy of Management Journal, 57(2), 515-540.

Redding, G., \& Drew, A. (2015). Dealing with the complexity of causes of societal innovativeness: Social enabling and disabling mechanisms and the cases of China. Journal of Interdisciplinary Economics, 28(2), 130.

Redding, G. (2016). Impact of China's invisible societal forces on its intended evolution In A. Y. Lewin, M. Kenny, \& J. P. Murmann (Eds.), China's innovation challenge: Overcoming the middle-income trap, Cambridage University Press, Cambridge.

Riqueleme, H., \& Watson, J. (2002). Do venture capitalists' implicit theories on new business success/failure have empirical validity. International Small Business Journal, 20(1), 395-418.

Ritter, T., \& Gemünden, H. G. (2004). The impact of a company's business strategy on its technological competence, network competence and innovation success. Journal of Business Research, 57(5), 548-556.

Roy, P., \& Roy, P. (2004). The Hewlett Packard-Compaq computers merger: Insight from the resource-based view and the dynamic capabilities perspective. Journal of American Academy of Business Cambridge, 5(2), 7-14.

Schilling, M. A. (2008). Strategic management of technological innovation $\left(2^{\text {nd }}\right.$ ed.). New York, NY:
McGraw-Hill Education.

Schuler, D. (1996). New community networks: Wired for change. New York, NY: ACM Press.

Sidhu, J. S., Commandeur, H. R., \& Volberda, H. W. (2007). The multifaceted nature of exploration and exploitation: Value of supply, demand, and spatial search for innovation. Organization Science, 18(1), 20-38.

Smits, R. (2002). Innovation studies in the 21th century: Questions from a user's Perspective. Technological Forecasting \& Social Change, 69(2), 861-883.

Sneddon, J. N., Soutar, G. N., \& Mazzarol, T. W. (2009). A socio-cognitive perspective of industry innovation initiatives. Prometheus, 27(3), 251-265.

Srichan, T., Tachaphahapong, S., \& Methakunavudhi, P. (2016). A factor analysis of leadership in the twenty first century of student organization board. Journal of Research Methodology, 29(2), 1-17.

Teece, D. J. (2014). The foundations of enterprise performance: Dynamic and ordinary capabilities in an (economic) theory of firms. The Academy of Management Perspectives, 28(4), 328-352.

Tiwana, A., \& Mclean, E. R. (2005). Expertise integration and creativity in information systems development. Journal of Management Information Systems, 22(1), 1343.

Tong, C. K. (2014). Rethinking Guanxi and Trust in Chinese Business Networks, Chinese Business. NewYork, NY: Springer.

Tsai, K.-H., Hsieh, M. H., \& Hultink, E. J. (2011). External technology acquisition and product innovativeness: The moderating roles of R\&D investment and configurational context. Journal of Engineering and Technology Management, 28(3), 184-200.

Utterback, J. M., \& Suarez, F. F. (1993). Innovation, competition, and industry structure. Research Policy, 22(1), 1-21.

Wade, M., \& Hulland, J. (2004). Review: The resourcebased view and information systems research: Review, Extension and suggestions for future research. MIS Quarterly, 28, 1-12.

Walter, A., Auer, M., \& Ritter, T. (2006). The impact of network capabilities and entrepreneurial orientation on university spin-off performance. Journal of Business Venturing, 21(4), 541-567.

Wiratchai, N. (1999). LISREL: Statistical analysis for research $\left(3^{\text {rd }}\right.$ ed.). Bangkok, Thailand: Chulalongkorn.

Yang, C., \& Chen, L. C. (2007). Can knowledge capabilities affect the knowledge sharing behavior. Journal of Information Science, 33(1), 93-107.

Zhang, J., \& Duan, Y. (2010). The impact of different types of market orientation on product innovation performance: Evidence from Chinese manufacturers. Management Decision, 48(6), 849-867.

Zollo, M., \& Winter, S. G. (2002). Deliberate learning and the evolution of dynamic capabilities. Organization Science, 13(3), 339-353. 